\title{
A ATUAÇÃO DOS TRIBUNAIS DE CONTAS NO EXERCÍCIO DO CONTROLE EXTERNO SOBRE AS POLÍTICAS PÚBLICAS RELACIONADAS AO ENSINO MÉDIO
}

\section{ARTIGO ORIGINAL}

SILVA, Jadson Luís da ${ }^{1}$

STASSUN, Cristian Caê Seemann²

SILVA, Jadson Luís da. STASSUN, Cristian Caê Seemann. A atuação dos tribunais de contas no exercício do controle externo sobre as políticas públicas relacionadas ao ensino médio. Revista Científica Multidisciplinar Núcleo do Conhecimento. Ano 04, Ed. 08, Vol. 05, pp. 50-64. Agosto de 2019. ISSN: 2448-0959

\section{RESUMO}

O presente artigo apresenta a atuação dos Tribunais de Contas no exercício do controle externo sobre as políticas públicas voltadas ao ensino médio, etapa crítica do ensino público. A pesquisa foi implementada por meio de verificação da bibliografia acerca da matéria, diplomas legais que norteiam a atuação do controle externo e dados técnicos extraídos de relatórios de auditorias, inspeções e pareceres. Busca explanar o importante papel dos Tribunais de Contas como instrumento de indução e efetivação de políticas públicas no cenário brasileiro, a partir da contextualização do

${ }^{1}$ Especialização em Administração e Auditoria Aplicada ao Controle Externo pela Universidade do Estado de Santa Catarina - UDESC, e Graduação em Administração pela Universidade do Estado de Santa Catarina - UDESC/Escola Superior de Administração e Gerência - ESAG.

2 Pós-Doutorado em Educação (Universidade Federal de Santa Catarina), Doutorado em Ciências Humanas (UFSC), Doutorado Sanduíche em Comunicação (Università di Roma), Mestrado em Psicologia (UFSC), Especialização em Psicologia Clínica e Graduação em Psicologia. 
controle inserido na sociedade globalizada com novos paradigmas alicerçados na doutrina contemporânea constitucional. Assim, objetiva-se superar a ideia do controle meramente formal, que é limitado aos aspectos pertinentes à legalidade e conformidade dos atos, buscando no texto constitucional valores que proporcionem uma atuação direcionada para a análise qualitativa das políticas públicas.

Palavras-chave: Tribunais de contas, políticas públicas, ensino médio.

\section{INTRODUÇÃO}

O presente trabalho busca evidenciar como o controle externo a cargo dos Tribunais de Contas sobre as políticas públicas voltadas ao ensino médio desenvolvidas pelo Estado, podem garantir não apenas a legalidade e regularidade da aplicação dos recursos públicos, mas, precipuamente, contribuir para a efetividade das políticas sociais e dos serviços prestados pelo Estado, diminuindo as desigualdades na área da educação, com foco no ensino médio.

Como metodologia, foi realizada pesquisa bibliográfica acerca da temática, doutrina, legislação e jurisprudência que regem e norteiam a atuação do controle externo, textos referenciais sobre política social, pesquisa documental na internet, artigos e notícias veiculadas na mídia sobre o ensino médio e suas desigualdades no país, bem como dados técnicos extraídos de pareceres, relatórios de auditorias e inspeções realizadas pelo Tribunal de Contas do Estado de Santa Catarina.

Dados apresentados pelo Instituto Nacional de Estudos e Pesquisas Educacionais Anísio Teixeira (Inep), responsável pela aplicação do Pisa no Brasil, mostram que há no país grande desigualdade entre os estados em relação aos resultados do exame. Em ciências, o estado que obteve a maior pontuação foi o Espírito Santo, com 435 pontos. O estado com o pior desempenho foi Alagoas, com 360 pontos. De acordo com os critérios da organização, 30 pontos no Pisa equivalem a um ano de estudos. Isso significa que, em média, há mais de dois anos de diferença entre os dois estados. A média do Brasil em ciências foi de 401 pontos. 
Em leitura, cuja média do Brasil foi de 407 pontos, e em matemática, cuja média foi 377, 15 estados ficaram abaixo da média nacional: Roraima, Mato Grosso, Rio de Janeiro, Pará, Pernambuco, Rondônia, Amapá, Paraíba, Rio Grande do Norte, Piauí, Sergipe, Maranhão, Tocantins, Bahia e Alagoas (AGÊNCIA BRASIL, 2016).

Destaque-se que entre os fatores relatados pelo INEP no cenário brasileiro que acabam repercutindo de forma considerável, é o baixo desempenho dos alunos do ensino médio. Outro aspecto, está o índice de repetência que, entre outros fatores, pode realmente desestimular os estudantes.

O fator socioeconômico também influencia, repercutindo no mau desempenho escolar. No entanto, pesquisas relatam que alunos com maior nível socioeconômico, geralmente tendem a tirar notas maiores.

O quadro educacional do ensino médio brasileiro não melhorou a qualidade, ainda é negativo, e nem a equidade nos últimos 13 anos.

Diz a Secretária Executiva do Ministério da Educação (MEC), Maria Helena Guimarães de Castro: "A única melhora do país foi no fluxo. É importante registrar que $77 \%$ dos estudantes que fizeram o Pisa estão no ensino médio" (AGÊNCIA BRASIL, 2016).

\section{O ESTADO DE BEM-ESTAR SOCIAL: O WELFARE STATE}

O Estado de Bem Estar Social (Welfare State) surgiu, no início do século XX, como uma saída para a manutenção do modelo econômico capitalista em um momento histórico no qual as mazelas sociais do capitalismo exacerbado abriam as portas para a implantação de um sistema econômico baseado na apropriação coletiva dos meios de produção, seguindo o modelo soviético inserido com a Revolução Russa de 1917. Assim, à classe burguesa, beneficiada pelo liberalismo econômico, restou a seguinte alternativa: ou flexibilizava o modelo capitalista, possibilitando a proteção do proletariado explorado através da previsão de leis trabalhistas e outros benefícios 
sociais, ou corria o risco de ver eclodir outra revolução, agora, contrária aos interesses burgueses.

A mudança do modelo de Estado adotado teve reflexos na ordem jurídica, pois se, durante o Estado Liberal o foco eram os direitos individuais, em especial, a liberdade, na era do Estado de Bem-Estar Social, as atenções voltam-se para os direitos sociais que passam a constar das Constituições do século XX como são exemplo a Carta mexicana de 1917 e a Constituição de Weimar de 1919.

Em conseqüência da implantação do Estado Social, advieram algumas mudanças importantes no âmbito jurídico, a exemplo da emancipação do direito do trabalho como ramo autônomo da ciência jurídica e o aumento das normas de ordem pública a fim de limitar a autonomia da vontade. Neste rol, merece especial relevo, o reconhecimento da segunda dimensão dos direitos fundamentais, no direito positivo. Estes direitos caracterizam-se por concederem ao indivíduo direitos a prestações sociais frente ao Estado, impondo-Ihe o dever de atender a prestações positivas a serem implementadas através de políticas públicas. Vê-se, assim, que enquanto o Estado Liberal legitima-se através de uma abstenção ou não-intervenção, garantindo-se proteção à esfera privada dos indivíduos, o Estado Social legitima-se, ao contrário, pela atuação no meio social e implemento dos programas de governo e da efetividade dos direitos, especialmente os de cunho prestacional (BANDEIRA DE MELLO, 2003, p. 130).

É certo que as Constituições retratam a opção política e econômica do Estado e da sociedade. Assim, enquanto as Constituições Defensivas, próprias do Estado Liberal, exigiam um Estado minimalista, cuja intervenção se justificava apenas para proteger e garantir as liberdades do indivíduo, as Constituições Constitutivas ou Dirigentes, típicas do Estado de Bem Estar Social propõem um Estado interventor, com metas e planos de governo preconizados na Constituição, especialmente nos setores econômico e social. Nesse momento, configura-se um Estado que tem compromissos sociais, cuja efetividade depende da atuação dos órgãos políticos e judiciais. 
O Estado Social, portanto, não se contenta em garantir a mera igualdade formal de todos perante a lei, sendo necessário atingir a igualdade material, de modo que as pessoas possam ter as mínimas condições para usufruir a liberdade que thes era garantida apenas formalmente. Há, portanto, uma nítida interdependência entre os direitos fundamentais. Não basta a garantia legal do direito à liberdade individual, se o sistema social não for suficientemente equânime para que as pessoas possam ter as condições materiais que Ihes possibilitem exercer essa liberdade.

Sobre as distinções entre a igualdade formal e material acima mencionada esclarece Piovesan (1998), enfocando a mudança de perspectiva constitucional acarretada pelo advento do Estado de Bem Estar Social, in verbis:

A igualdade converte-se, assim, em valor essencial do sistema constitucional, tornando-se critério imperativo para a interpretação constitucional em matéria de direitos sociais. Eleva-se o direito à igualdade a direito-guardião do Estado Social. Transita-se, neste momento, da igualdade jurídica formal do Liberalismo para a igualdade material do Estado Social contemporâneo. Não se trata mais de uma igualdade perante a lei, mas de uma igualdade feita pela lei e através da lei (PIOVESAN, 1998, p. 35).

Houve, portanto, uma mudança de entendimento sobre a abrangência do princípio jurídico da igualdade que passou a consagrar a necessidade de atuação e intervenção estatal para possibilitar a realização da justiça social. Tal compromisso de fazer cumprir os direitos fundamentais, sobretudo os sociais e econômicos está retratado nas Constituições Constitutivas ${ }^{[3]}$, dirigindo-se não somente ao Legislativo e Executivo, como também ao Judiciário, Ministério Público e ao Tribunal de Contas.

A atuação dos órgãos e poderes acima referidos deve ser, sob a ótica da Constituição Dirigente, promocional a fim de efetivar os direitos fundamentais previstos na Constituição. 
Vê-se, assim, que as Constituições Dirigentes ou Constitutivas traçam, normativamente, programas de atuação política, estabelecendo metas e prioridades de cunho econômico, social e cultural a serem alcançadas, vinculando todos os órgãos de direção política. Tais Constituições não se restringem a organizar o poder político e repartir competências, vão além, pois propõem uma conformação da atuação política do Estado visando a realização da igualdade material no seio da sociedade.

\section{CLASSIFICAÇÃO DOS DIREITOS FUNDAMENTAIS SOCIAIS}

Para tratar da classificação dos direitos sociais, primeiro é necessário esclarecer que os direitos fundamentais exercem, segundo a proposta de classificação trazida por Ingo Sarlet, inspirado nas lições de Robert Alexy, variadas funções, podendo ser entendidos como direitos de defesa ou direitos a prestações (SARLET, 1998, P. 180).

Assim, os direitos fundamentais como direitos de defesa tem por objetivo proteger a autonomia individual, assegurando ao indivíduo o direito de repelir intervenções abusivas no exercício de sua liberdade. Dessa forma, os direitos de defesa demandam do Estado e de particulares uma abstenção. Identificam-se nessa categoria, predominantemente, os direitos de primeira dimensão tais como o direito de liberdade, de igualdade formal, direito à vida e à propriedade, vinculados ao ideário do Estado Liberal.

Já os direitos fundamentais como direitos a prestações, ao contrário, demandam dos destinatários da norma, sobretudo dos poderes públicos, uma conduta ativa no sentido de proporcionar aos indivíduos os meios materiais necessários ao exercício de uma liberdade efetiva, promovida pela intervenção do Estado na ordem econômica e social a fim de garantir a igualdade material. Tais direitos a prestações vinculam-se, principalmente, à segunda dimensão dos direitos fundamentais e aos postulados do Estado Social. Isto não significa, porém, que existam direitos a prestações, apenas, no âmbito dos direitos sociais, pois, como bem esclarece INGO W. SARLET, o direito dos partidos políticos aos 
recursos do fundo partidário(art. 17, parágrafo $3^{\circ}$ da CF) e o direito de acesso à justiça e à assistência jurídica integral e gratuita (art. 5ํㅡ, incisos XXXV e LXXIV da CF) demonstram que direitos prestacionais podem ser encontrados no rol dos direitos individuais e políticos, não se limitando apenas aos direitos sociais (SARLET, 1988, P. 15).

Dando continuidade à classificação dos direitos fundamentais a prestações, pode-se subdividi-los em: 1 . direitos a prestações em sentido completo acaba incluindo os direitos à proteção e de participação em procedimento; 2 . direitos a prestações em sentido estrito que preveem uma prestação material a ser fornecida, no mais das vezes, pelo Estado, dentro da concepção do Estado de Bem Estar Social. Com efeito, é nesta derradeira categoria que se enquadram os direitos sociais prestacionais como a saúde, educação, moradia, assistência, previdência, dentre outros enunciados no art. 6º da Constituição Federal.

É certo que no âmbito dos direitos sociais prestacionais é mais evidente a necessidade de recursos econômicos e a demanda por formulação e o implemento de políticas públicas a cargo, precipuamente, do Legislativo e Executivo. No entanto, ressalte-se que os direitos de defesa também carecem de investimento público para sua efetivação, além da infra-estrutura institucional e procedimental de órgãos estatais capazes de assegurar a manutenção da ordem pública e o exercício do direito de liberdade pelos indivíduos.

Assim, por exemplo, para que seja possível assegurar o direito de ir e vir das pessoas, é necessário que o Estado tenha tanto uma postura de respeito e não intervenção na esfera de liberdade individual, quanto também é necessária a existência de instrumentos processuais como o habeas corpus e a própria estrutura do Poder Judiciário garantindo o direito de ir e vir das pessoas contra quaisquer violações.

Nessa hipótese, a garantia do direito de liberdade demanda o investimento público em recursos financeiros e humanos seja para custear a estrutura do Judiciário, seja para capacitar os agentes estatais, em especial, a polícia militar para que tenham a conduta 
de respeito aos direitos humanos e, no caso mencionado, não interfiram na liberdade de ir e vir das pessoas em situações de normalidade social.

Até que ponto, então, pode-se aceitar sem reservas o argumento de menor eficácia dos direitos sociais prestacionais tendo em vista a escassez de recursos públicos? Os recursos financeiros arrecadados pelo Estado devem obedecer a uma ordem de prioridades orçamentárias tendo em vista a dignidade da pessoa humana. Isto porque, se a dignidade do homem é o fundamento do Estado brasileiro e o implemento dos direitos sociais é imprescindível para se viver dignamente, por que a falta de recursos financeiros é, em geral, o principal obstáculo à plena eficácia dos direitos sociais prestacionais? A definição das despesas públicas deve, então, ficar ao largo do controle? Essas são questões que terão desenvolvimento em sede própria, mas estão sendo levantadas no momento apenas por ter relação com os direitos de defesa e os direitos sociais prestacionais, de acordo com a classificação mencionada.

A classificação funcional dos direitos fundamentais é útil para a identificação das diferenças entre as diversas classes de direitos fundamentais e as funções preponderantes, em especial, no que se relaciona ao objeto da prestação e à estrutura normativa dos direitos de defesa e dos direitos prestacionais. Todavia, em nosso entender, tais diferenças não devem servir ao argumento de menor eficácia dos direitos fundamentais sociais, elas apenas apontam que a eficácia desses direitos carece de maior esforço dos poderes públicos.

\subsection{DA EFICÁCIA DOS DIREITOS SOCIAIS PRESTACIONAIS}

O Estado Social como já mencionado surgiu da necessidade de se reconhecer certos direitos sociais, econômicos e culturais decorrentes de reivindicações políticas das classes operárias que passaram a se organizar para combater os graves problemas sociais resultantes do processo de industrialização e da adoção de um sistema capitalista sem freios éticos.

Assim, após a Primeira Guerra Mundial esses direitos de segunda dimensão passaram a ser reconhecidos na ordem constitucional de 
diversos Estados de Direito como é o caso da Constituição de Weimar de 1919 que, em face da ampla sistematização adotada para os direitos de cunho social, contribuiu para a formulação do Estado Social brasileiro em 1934 até os dias atuais (LASSALE, 2001, p. 90).

Não obstante o reconhecimento constitucional dos direitos sociais e econômicos tenha sido um passo importante na conquista histórica dos direitos fundamentais, não é, por si só, suficiente para garantir sua eficácia. Com efeito, por tais direitos solicitarem do Estado uma maior atuação na formulação e implemento de políticas públicas e dependerem, para sua efetivação, de verbas e investimento público, houve quem sustentasse que os direitos sociais não possuíam juridicidade. Sua eficácia foi, inicialmente, negada, pois estaria condicionada à existência das condições financeiras e materiais para atender o comando constitucional. Além disso, as normas de cunho social foram consideradas, ao menos em sua maioria, de caráter programático, pois em face da sua baixa densidade normativa, dependeriam de complementação legislativa para terem plena eficácia.

Assim, por muito tempo, considerou-se que as normas constitucionais consagradoras de direitos sociais, seriam apenas declarações de boas intenções, sem o caráter jurídico obrigacional, constituindo-se em valores éticos da sociedade. Não se admitia a existência de relação jurídica obrigacional entre o cidadão e o Estado (na qual o primeiro figurasse na posição de credor e o segundo como devedor de prestações sociais) ao fundamento de que não se poderia reconhecer ao cidadão direito público subjetivo em face do Estado, pois o dever do Estado em relação aos direitos de educação e saúde teria, apenas, conteúdo moral, de orientação ao bom administrador público, sem constituir um vínculo obrigacional (CRETELLA JUNIOR, 1988, p 884).

Tal posicionamento encontra-se teoricamente ultrapassado, e com razão, devendo-se reconhecer aos direitos fundamentais sociais, ao menos, uma eficácia jurídica mínima consistente, dentre outras coisas, em revogar as normas que lhes sejam contrárias e impedir que haja atuação normativa ou material em confronto com o conteúdo 
essencial e incontroverso do direito fundamental traçado na Constituição, sob pena de declaração de inconstitucionalidade.

No entanto, deve-se salientar que hoje, de acordo com a moderna doutrina ${ }^{[4]}$ constitucional, tem-se buscado reconhecer maior eficácia jurídica aos direitos fundamentais, em especial, os de cunho social, atribuindo-Ihes uma eficácia normativa e vinculante aos Poderes Públicos.

De acordo com o art. 5, parágrafo 1ํ da Constituição Federal, vê-se que "as normas definidoras dos direitos e garantias fundamentais têm aplicação imediata". Não obstante tal norma esteja situada no capítulo dos direitos individuais e coletivos, sua incidência estende-se aos demais direitos fundamentais previstos na Constituição brasileira e nos tratados internacionais de que o Brasil faça parte, incluindo-se os direitos sociais prestacionais. Isto em decorrência não somente da interpretação literal da expressão "direitos e garantias fundamentais", como também em face da interpretação teleológica, haja vista que o Constituinte brasileiro, como se sabe, não previu regimes jurídicos distintos para direitos fundamentais de defesa ou prestacionais, ao contrário, os tratou de modo uniforme a despeito das diferenças na estrutura normativa.

Mas, no tocante à norma que prevê a aplicabilidade imediata dos direitos fundamentais, o que realmente importa é saber qual sua interpretação em face dos direitos sociais prestacionais. Em outras palavras, como entender que um direito social que carece de prestação estatal fática possa ser imediatamente aplicável?

Diversas posições são encontradas na doutrina nacional. Sarlet (1998) entende que o art. $5^{\circ}, \S 1^{\circ}$, da Constituição Federal deve ser compreendido como um princípio, nas suas palavras, um "mandado de otimização" em que se "estabelece para os órgãos estatais a tarefa de reconhecerem, à luz do caso concreto, a maior eficácia possível a todas as normas definidoras de direitos e garantias fundamentais" (p. 29). 


\section{A ATUAÇÃO DOS TRIBUNAIS DE CONTAS NO EXERCÍCIO DO CONTROLE EXTERNO SOBRE AS POLÍTICAS PÚBLICAS RELACIONADAS AO ENSINO MÉDIO}

Os Tribunais de Contas no cenário brasileiro, com a promulgação da Constituição Federal de 1988, adquiriram uma nova conotação como também novas competências, maior autonomia administrativa e financeira, e a partir desse contexto tornou-se um órgão totalmente independente em relação a qualquer dos Poderes do Estado.

Conforme assevera Santana (2016), o Tribunal de Contas da União passou a ter competência na área de fiscalização contábil, financeira, orçamentária, operacional e patrimonial do governo, bem como das entidades da administração direta e indireta, quanto à legalidade, legitimidade, eficácia e economicidade.

Os Tribunais de Contas começaram a exercer as suas funções pautadas em uma nova perspectiva de controle da administração pública no contexto atual, onde os órgãos de controle externo podem contribuir de forma significativa e decisiva no aspecto de buscar proteger os direitos dos cidadãos. Isso ocorreu devido ao estreitamento das relações dos órgãos de controle e da própria sociedade ao procurar incrementar a fiscalização dos gastos públicos e afastar-se da simples verificação da formalidade dos atos.

Assim, houve um aumento da efetividade das políticas sociais e públicas, bem como dos próprios serviços prestados pelas Cortes de Contas, contribuindo para fortalecer a cidadania e, consequentemente, o regime democrático brasileiro.

Ressalta-se ainda, a importância dos órgãos de controle externo na defesa dos direitos fundamentais ao desempenharem suas atribuições constitucionais.

É essencial nesse novo cenário econômico, que o controle da gestão pública, bem como da realização da aplicação dos recursos financeiros que são desempenhados pelo Estado, sejam impreterivelmente implementados sempre de forma autônoma e independente, de tal modo que sejam convertidos em benefício da própria população 
que compõe este Estado, e também poder atuar de forma ativa, proibindo os desperdícios e desvios das verbas públicas.

Na conjuntura brasileira da última década, os gastos públicos na estrutura educacional apresentaram significativo crescimento quando comparados e verificados de acordo com o PIB nacional. A expectativa é de que esses gastos continuem crescendo nas três esferas de governo, tanto em valores reais quanto em relação ao PIB, em decorrência, fundamentalmente, das metas fixadas no Plano Nacional de Educação PNE, de ampliar o investimento público em educação para 7\% do PIB, no quinto ano de vigência do plano, e para 10\% do PIB ao final da sua vigência, em 2024.

É desafiante o ensino médio no cenário brasileiro, pois são vários aspectos que dificultam a garantia do acesso e, além disso, conseguir que os jovens concluam essa etapa do ensino.

Segundo o Tribunal de Contas da União (2016), outro ponto desafiador para as políticas públicas no contexto nacional, é procurar a redução das desigualdades indicadas pelos índices analisados pelo IDEB - Índice de Desenvolvimento da Educação Básica, entre as redes pública e privada e entre estados. Uma Auditoria coordenada do Tribunal de Contas da União com 28 tribunais de contas brasileiros apurou: deficiências de gestão e infraestrutura da rede; déficit de professores; excesso de docentes sob o regime de contratação temporária; diferenças significativas na contabilização de gastos; indefinição de valor mínimo por aluno como parâmetro da complementação da União ao Fundeb; e falta de regulamentação de padrões mínimos de qualidade.

Do estudo e acompanhamento da gestão na área educacional do Estado de Santa Catarina, especificamente o ensino médio no período de 1998 a 2018, verificou-se que o Tribunal de Contas do Estado de Santa Catarina (TCE/SC) evidenciou em pareceres (SANTA CATARINA, 2017) e relatórios de auditorias efetuadas (TCE, 2018), restrições que merecem destaque: desvio de finalidade e má aplicação dos recursos públicos; ineficiência das políticas públicas: planejamento, implementação e acompanhamento inadequados; inadequação em relação aos equipamentos 
destinados ao ensino e à manutenção das escolas; política salarial bem como programas de capacitação e atualização que não valorizam devidamente os profissionais do magistério; descumprimento do orçamento destinado ao ensino médio, consoante previsão na Lei Orçamentária Anual, deixando de executar toda a programação orçamentária e financeira estabelecida.

Em decorrência do apurado, o Tribunal de Contas de Santa Catarina encaminhou recomendações e determinações à Secretaria de Estado da Educação de Santa Catarina visando sanar as irregularidades, bem como aplicou as sanções cabíveis previstas em lei.

Diante disso, observou-se o estabelecimento de ações corretivas por parte de Secretaria de Estado da Educação objetivando solucionar os problemas levantados nas auditorias e inspeções implementadas pelo Tribunal de Contas do Estado, entretanto, foram insuficientes para reverter o quadro de má gestão das políticas públicas e ineficiência na aplicação dos recursos públicos destinados ao ensino médio.

O acima exposto expõe a necessidade de reforçar a implementação de auditorias operacionais e monitoramentos periódicos no âmbito do Tribunal de Contas do Estado, como instrumento de avaliação e efetividade das políticas públicas voltadas ao ensino médio.

A atuação da Corte de Contas na avaliação das políticas públicas contribuirá para a eficiência do gasto público, assim como para o desenvolvimento dos direitos sociais e redução das desigualdades.

Registre-se, por oportuno, que a fiscalização legal-formal não é suficiente para o atendimento do interesse público. Faz-se necessário incentivar e ampliar a possibilidade de participação da sociedade (controle social) no exercício do controle. 


\section{CONCLUSÕES}

Ao desenvolver a temática do controle externo a cargo dos Tribunais de Contas sobre as políticas públicas relacionadas ao ensino médio que, em síntese, versa sobre a implementação dos direitos sociais no campo educacional, através da atuação do Tribunal de Contas, verifica-se a conformidade com os objetivos previstos no art. 3ํㅡ, da Constituição Federal, que, em última análise, buscam a promoção da justiça social.

Dessa forma, a previsão do princípio basilar da dignidade da pessoa humana como fundamentação do Estado brasileiro, busca reforçar a compreensão de que a razão de ser do Estado é promover o bem de todos.

A dignidade do homem contemporâneo no contexto atual, como valor socialmente aferível, vai muito além do aspecto meramente subjetivo tanto das qualidades morais e éticas da pessoa, pois demanda um envolvimento da existência de condições materiais mínimas para que ele possa sobreviver e se desenvolver de forma livre. Mas, para que isso ocorra, é fundamental que o Estado de Bem-Estar Social possa garantir a efetividade dos direitos sociais brasileiros.

Nessa conjuntura, perante a norma constitucional brasileira que preconiza a aplicação dos direitos fundamentais aos cidadãos, é que se verifica a importância da atuação do controle externo a cargo dos Tribunais de Contas sobre as políticas públicas voltadas ao ensino médio, devendo atuar em busca da economicidade, eficiência e efetividade.

Portanto, almeja-se que, no futuro, os direitos sociais no campo educacional alcancem plena efetividade na promoção de um ensino médio com qualidade.

No entanto, fica nítida a importância da intervenção dos Tribunais de Contas que, ao cumprirem o seu papel relevante na efetivação dos direitos sociais prestacionais, contribuirão sobremaneira para minimizar as desigualdades e mazelas do ensino médio no Brasil. 


\section{REFERÊNCIAS}

AGÊNCIA BRASIL. Pisa: quase metade dos estudantes tem desempenho menor que o adequado. Disponível em: http://agenciabrasil.ebc.com.br/educacao/noticia/201612/quase-metade-dos-brasileiros-tem-desempenho-menor-que-o-adequado-no-pisa. Acessado em 10.12.2016.

ARAÚJO, Luiz Alberto David; NUNES JÚNIOR, Vidal Serrano. Curso de direito constitucional. 6⿳⺈ ed., rev. e atual. - São Paulo: Saraiva, 2002.

BANDEIRA DE MELLO, Celso Antônio. Curso de direito administrativo. 15aㅡ ed., ref., amp. e atual. até a Emenda Constitucional n.39 de 19.12.2002.- São Paulo: Malheiros, 2003.

CRETELLA JÚNIOR, José. Comentários à constituição de 1988. V.II, Rio de Janeiro: Forense, 1988.

LASSALLE, Ferdinand. A essência da constituição. $6^{\underline{a}}$ ed. - Rio de Janeiro: Lumen Juris, 2001.

PIOVESAN, Flávia. Temas de direitos humanos. São Paulo: Max Limonad, 1998.

SANTA CATARINA. Tribunal de Contas. Relatórios e pareceres prévios sobre as contas do Governo do Estado: exercícios 2009-2016. Florianópolis: TCE, 2017.

SANTANA, Herick Santos. Controle externo da administração pública. Revista Jus Navigandi, Teresina, ano 19, n. 3894, 28 fev. $2014 . \quad$ Disponível em: <https://jus.com.br/artigos/26798>. Acesso em: 16.12.2016.

SARLET, Ingo Wolfgang. A eficácia dos direitos fundamentais. $4^{a}$ ed. rev., atual. e ampl. - Porto Alegre: Livraria do Advogado Editora, 2004.

SARLET, Ingo Wolfgang. "Os direitos fundamentais sociais na Constituição de 1988". Revista Diálogo Jurídico. Ano I, Vol. I, № 1, Abril de 2001. Salvador, Bahia, Brasil. Encontrado no site: DireitoPublico.com.br. 
SARMENTO, Daniel. Direitos fundamentais e relações privadas. - Rio de Janeiro: Lumen Juris, 2004.

SILVA, José Afonso da. Aplicabilidade das normas constitucionais. $3^{\underline{a}}$ ed. São Paulo: Malheiros, 1998.

TCE/SC. Relatórios de auditorias realizadas na Secretaria de Estado da Educação/SC, versando sobre a execução orçamentária e financeira, e auditoria operacional no ensino médio oferecido pela Secretaria Estadual de Educação. 19982018. Tribunal de Contas do Estado. Florianópolis, 2018.

TCU. TCU: Controle externo e políticas públicas. Disponível em:http://portal.tcu.gov.br/data/files/web.pdf. Acessado em 16.12.2016

3. O uso da expressão "Constituição Constitutiva" foi empregado por Flávia Piovesan na obra retrocitada para designar aquelas constituições que surgiram sob a ideologia do Estado Social e para contrapor à ideia de "Constituição Defensiva", própria do Estado Liberal em que se procurava defender o cidadão da possível violência e opressão que pudessem ser exercidas pelo Estado contra o indivíduo, resguardandoo na sua liberdade, segurança e propriedade.

4. Como moderna doutrina entenda-se, dentre outras, as obras: Constituição Dirigente e Vinculação do Legislador: Contributo para a compreensão das Normas Constitucionais Programáticas, de José Joaquim Gomes Canotilho; A Eficácia dos Direitos Fundamentais, de Ingo Wolfgang Sarlet; O Direito Constitucional e a Efetividade de suas Normas Constitucionais de Luís Roberto Barroso.

Enviado: Agosto, 2019.

Aprovado: Agosto, 2019. 